\title{
Índice de Compromisso Religioso (ICR): Elaboração e Evidências Psicométricas
}

\author{
Religious Commitment Index (RCI): Elaboration and Psychometric Evidences
}

\author{
Walberto S. dos Santos ${ }^{*}, a$, Valdiney V. Gouveia ${ }^{b}$, Valeschka Martins Guerra ${ }^{c}$, \\ Márcio de L. Coutinho ${ }^{b} \&$ Darlene P. Fernandes ${ }^{a}$ \\ ${ }^{a}$ Universidade Federal do Ceará, Fortaleza, Brasil, ${ }^{b}$ Universidade Federal da Paraíba, João Pessoa, Brasil \\ $\&^{c}$ Universidade Federal do Espírito Santo, Vitória, Brasil
}

\begin{abstract}
Resumo
Este artigo descreve o desenvolvimento do Índice de Compromisso Religioso (ICR), que busca unir diferentes dimensões do compromisso religioso em um único índice, mediante dois estudos. Participaram desses estudos 317 estudantes (Estudo 1) e 194 pessoas (Estudo 2), com médias de idade semelhantes (Estudo 1: $m=16,6, D P=5,20$; Estudo $2: m=16, D P=4,41)$, a maioria mulheres $(53,6 \%$ e $67,5 \%$, respectivamente). Os participantes responderam a uma escala de crenças e outra de práticas religiosas, além de perguntas sobre religiosidade e sóciodemográficas. Os estudos demonstraram as diferentes dimensões agrupando-se em um único fator, explicando $65 \%$ da variância total e apresentando consistência interna satisfatória. Tais resultados sugerem a adequação da $I C R$ para utilização nos grupos religiosos estudados.
\end{abstract}

Palavras-chave: Religião, religiosidade, compromisso religioso, crença.

\begin{abstract}
This paper describes the development of the Religious Commitment Index ( $R C I)$ which aims at grouping different dimensions of religious commitment in one single index by conducting two studies. Three hundred seventeen students took part in Study 1 and 194 people in Study 2, with similar mean ages (Study 1: $m=16.6, S D=5.20$; Study $2: m=16, S D=4.41)$, mostly female $(53.6 \%$ and $67.5 \%$, respectively). All participants completed one scale of religious beliefs and one of religious practices, followed by religious related and socio-demographic questions. Both studies showed the different dimensions grouping in one single factor, accounting for $65 \%$ of the total variance and showing satisfactory internal consistency. The results suggest the adequacy of the RCI for the studied religious groups.

Keywords: Religion, religiosity, religious commitment, belief.
\end{abstract}

A religião pode ser considerada uma manifestação característica da humanidade, presente em todas as raças e culturas, o que a faz ser compreendida como um fenômeno universal e tipicamente humano (Wilges, 1994). Nesta direção, entende-se que a experiência religiosa se desenvolve por meio da vida em sociedade, configurando-se como uma variável importante pela influência que tem nas atitudes, valores e comportamentos das pessoas, tanto em nível individual como social (Schwartz \& Huismans, 1995).
O termo "religião", apesar de amplamente utilizado entre os cientistas sociais, não goza de unanimidade em suas definições (Mokhlis, 2009). No entanto, verificase uma convergência de ideias que incluem a dependência do homem em relação a um ser supremo e a necessidade de seguir determinadas crenças de cunho religioso (Mokhlis, 2009).

Os termos "religião" e "religiosidade" são utilizados muitas vezes como equivalentes, sugerindo que apenas indivíduos identificados com religiões organizadas possuem religiosidade. No entanto, traços e atitudes constituintes da religiosidade, tais como crer em um deus pessoal ou em uma realidade transcendente, a importância de crer em algo maior, ter momentos de oração ou contemplação, não estão associados a uma religião institucional específica (Cohen \& Hill, 2007), mas envolvem um compromisso individual com suas crenças e práticas espirituais. Segundo Witter (2007, p. 153), “define-se religiosidade como a importância atribuída e a freqüência de (a) crenças religiosas, (b) práticas religiosas, (c) aplicações das crenças e (d) participação nos serviços e atividades de grupo da religião". 
Considerando a religiosidade enquanto construto, sua estrutura fatorial não se constitui em um ponto pacífico para as ciências sociais. Schwartz e Huismans (1995) citam diversos estudos que abordam esta questão, reconhecendo que a medida de religiosidade como uni- ou multidimensional depende do propósito e contexto da pesquisa.

Considerar a religiosidade como multidimensional permite avaliar diferentes níveis de envolvimento, crenças, convicções e, consequentemente, do compromisso dos indivíduos com a religião que proferem. Para considerála como multidimensional, faz-se necessário identificar seus componentes, conceituá-los e operacionalizá-los.

Um modelo multidimensional proposto por Glock (1962) sugere a existência de cinco fatores básicos: (a) a experiência religiosa; (b) as convicções religiosas e a consistência dessas convicções; (c) o conhecimento que se possui acerca do sistema de crenças da religião; (d) as consequências éticas do envolvimento com uma denominação; e (e) a frequência com que se pratica os rituais religiosos. Este modelo têm o mérito de apresentar diferentes aspectos do fenômeno religioso, quando a maioria busca analisá-lo desde perspectivas dicotômicas, contrapondo religiosidades intrínseca e extrínseca (Allport \& Ross, 1967).

Pela semelhança de seu conteúdo, os termos "religiosidade" e "compromisso religioso" serão utilizados aqui como intercambiáveis. Espera-se que este conjunto de elementos possa ser integrado em um índice de compromisso religioso, favorecendo o consenso acerca da direção e magnitude de suas correlações com variáveis externas, além de assegurar a replicabilidade das pesquisas. Considerando estes aspectos, o presente artigo se propõe a descrever o desenvolvimento e as evidências de validade fatorial e consistência interna do Índice de Compromisso Religioso (ICR). Neste contexto, demanda-se discutir fatores que podem ser importantes para representar o construto de interesse.

\section{Medindo o Compromisso Religioso}

A literatura apresenta diferentes formas de medir o compromisso religioso. Uma das alternativas seria avaliá-lo por meio de crenças, conhecimentos, experiências, práticas rituais e práticas devocionais (Davidson, 1975; Finney, 1978). Apesar de seu caráter heurístico, o modelo apresentado por Finney (1978) parece pouco adequado para pesquisas que envolvem contextos caracterizados pela diversidade religiosa, pois não especifica os meios pelos quais estas variáveis poderiam ser mensuradas.

É importante aqui diferenciar compromisso e envolvimento religiosos (Longshore, Chang, Hsieh, \& Messina, 2004); embora compromisso implique envolvimento, o envolvimento religioso não necessariamente representa o compromisso. Em muitos casos, o compromisso é analisado a partir de itens que abordam o tempo gasto em atividades religiosas (Krohn, Massey, Skinner, \& Lauer,
1983). Contudo, apesar de a frequência de uma atividade religiosa ser uma variável importante neste contexto (Johnson, De Li, Larson, \& McCullough, 2000), não representa toda extensão do construto religiosidade. Estudos que utilizam itens exclusivamente desta natureza podem não obter dados confiáveis de seus participantes quanto à sua religiosidade. Portanto, são necessários outros fatores pesquisados em diversos estudos (Johnson et al., 2000), entre os quais a importância atribuída à religião na vida, o envolvimento religioso, as medidas de crença religiosa, as práticas religiosas, a participação em atividades ligadas à religião, o tempo dedicado a estas atividades e os valores relacionados com a religiosidade (Dalgalarrondo, Soldera, Corrêa Filho, \& Silva, 2004).

Como recomendado por Gorsuch e McFarland (1972), no presente estudo o compromisso religioso é concebido como a relação entre múltiplos indicadores, envolvendo aspectos centrais para a concepção de religiosidade. Buscou-se, então, identificar as dimensões contempladas como indicadoras do compromisso religioso. A primeira se referiu à religiosidade autopercebida; em termos específicos, reconhece-se que apesar de algumas pessoas confessarem não ter uma religião específica, elas tendem a assumir algum nível de religiosidade. Além disso, também são identificadas as crenças e as práticas específicas das religiões ou denominações religiosas; estima-se que indivíduos com compromisso religioso alto tendem a conhecer o sistema de crenças de seu grupo e apresentar coerência entre tais crenças e suas práticas. Consequentemente, pessoas comprometidas com a religião costumam ser fiéis na participação em reuniões e eventos ligados ao seu grupo religioso, apresentando crenças e práticas religiosas consistentes.

Em busca por artigos publicados no Brasil utilizando a palavra-chave 'religiosidade' no título, 33 artigos foram encontrados na base de dados do Scientific Electronic Library Online (SciELO, 2011). O resultado da busca indicou que quatro são de outras disciplinas (como História, por exemplo), quatorze enfatizam a importância da religiosidade em contextos de saúde e doença (ex.: Faria \& Seidl, 2005), e seis enfatizam a importância do tema para a saúde mental (ex.: Moreira-Almeida, Lotufo Neto, \& Koenig, 2006). Segundo Panzini, Maganha, Rocha, Bandeira e Fleck (2011, p. 154), "espiritualidade e religiosidade são frequentemente citadas como fatores protetores à saúde, representam características adaptativas da vida, segundo a Psicologia Positiva". Dentre os nove artigos restantes, cinco referem-se a temas variados, como o desenvolvimento da religiosidade na adolescência (Witter, 2007), a influência da religiosidade na sexualidade (Silva, Santos, Licciardi, \& Paiva, 2008) ou a importância da religiosidade como fator de proteção para o uso de drogas (Sanchez \& Nappo, 2007).

Apenas quatro artigos foram publicados com referência ao desenvolvimento ou validação de escalas psicomé- 
Santos, W. S., Gouveia, V. V., Guerra, V. M., Coutinho, M. L. \& Fernandes, D. P. (2012). Índice de Compromisso Religioso (ICR): Elaboração e Evidências Psicométricas.

tricas relacionadas ao tema: dois deles informam sobre o desenvolvimento (Fleck, Borges, Bolognesi, \& Rocha, 2003) e validação brasileira (Panzini et al., 2011) do WHOQOL, módulo que investiga a religiosidade no instrumento sobre qualidade de vida da Organização Mundial de Saúde; um deles apresenta a validação da Escala de Religiosidade de Duke (Moreira-Almeida, Peres, Aloe, Lotufo Neto, \& Koenig, 2008), associando este construto à saúde mental, de acordo com dimensões identificadas como organizacional, não-organizacional e religiosidade intrínseca; e finalmente, um último instrumento descreve a elaboração de uma Escala de Coping Religioso-Espiritual (Panzini \& Bandeira, 2005), que elenca estratégias religiosas de enfrentamento frente à situações de crise.

Além dos instrumentos mencionados acima, duas escalas foram identificadas, tendo sido desenvolvidas no contexto brasileiro com o objetivo de mensurar aspectos diferentes da religosidade: Escala de Crenças Religiosas (Andrade, Gouveia, Jesus, Santos, \& Lopes de Andrade, 2001) e Escala de Práticas Religiosas (Meira, Gouveia, Socorro, Oliveira, \& Silva Filho, 2001). Apesar de serem compostas por um número reduzido de itens, não abarcando a diversidade de segmentos religiosos no Brasil, envolvem crenças e práticas dos grupos mais predominantes - católicos, espíritas e protestantes (Instituto Brasileiro de Geografia e Estatística [IBGE], 2010). Desenvolvidas para utilização na população geral (de crianças a idosos), ambas reúnem evidências de validade fatorial e consistência interna, embora empregando unicamente análises fatoriais exploratórias e Alfas de Cronbach. Neste sentido, por mensurarem crenças e práticas dos três principais grupos religiosos do país, podendo ser aplicadas à maioria da população brasileira, estas escalas foram escolhidas para compor o Índice de Compromisso Religioso.

Em resumo, o propósito último deste artigo é propor um Índice de Compromisso Religioso, conhecendo seus parâmetros psicométricos. Neste sentido, dois estudos foram realizados: o Estudo 1 tem o objetivo de investigar os parâmetros psicométricos das escalas utilizadas; e o Estudo 2 tem o objetivo de informar a construção do Índice de Compromisso Religioso (ICR) com base nessas escalas.

\section{Estudo 1. \\ Parâmetros Psicométricos das Escalas de Crenças e Práticas Religiosas}

Consideradas como indicadores de compromisso religioso e visando tê-las em conta para definir um índice a respeito, as medidas de crenças (Andrade et al., 2001) e práticas (Meira et al., 2001) religiosas precisam reunir evidências psicométricas complementares que assegurem sua adequação. Especificamente, objetiva-se neste estudo testar a estrutura fatorial observada em seus estudos originais, considerando amostras de crianças, jovens e adultos das três principais religiões do país.

\section{Método}

\section{Participantes}

Participaram 317 estudantes com idades variando de 10 a 45 anos $(m=16,6 ; D P=5,20 ; 86,2 \%$ com até 20 anos), sendo a maioria do sexo feminino $(53,6 \%)$. Destes, $34,3 \%$ eram estudantes do ensino fundamental, $40,7 \%$ do ensino médio e $25 \%$ do superior. Quanto à religião, estes se declararam católicos $(60 \%)$, evangélicos $(29 \%)$, espíritas (2\%) e sem religião (9\%). Esta foi uma amostra de conveniência (não-probabilística), considerando-se as pessoas que concordaram em participar do estudo. Como regras de exclusão, as seguintes foram consideradas: (a) indicar uma denominação religiosa diferente dos grupos cristãos estudados; (b) não responder a pelo menos uma das medidas; (c) deixar mais de $10 \%$ dos itens de uma medida sem resposta; (d) responder de forma diferente ou utilizando escala diferente da proposta no estudo; e (e) apresentar idade inferior a 10 anos.

\section{Instrumentos}

Os participantes responderam um livreto composto pelos seguintes instrumentos:

Escala de Crenças Religiosas (Andrade et al., 2001). Esta é composta por 18 itens equitativamente distribuídos em três crenças: católicas (ex.: imagens de santos devem ser respeitadas), protestantes (ex.: a vocação para o trabalho é um dom divino) e espíritas (ex.: é possível a comunicação com pessoas que já faleceram). Para respondê-los, o participante utiliza escala de sete pontos, variando de 1 (Discordo totalmente) a 7 (Concordo totalmente). Análises de consistência interna apresentaram os seguintes Alfas de Cronbach: 0,96 (crenças católicas), 0,93 (crenças espíritas) e 0,65 (crenças protestantes).

Escala de Práticas Religiosas (Meira et al., 2001). Composta por 16 itens, esta escala mensura práticas de três grupos religiosos: católicos (ex.: rezar o terço), espíritas (ex.: ler livros psicografados) e protestantes (ex.: pregar o evangelho para outras pessoas). Estes são respondidos em escala de cinco pontos, variando de 1 (Nunca) a 5 (Sempre). Análises de consistência interna apresentaram os seguintes Alfas de Cronbach: 0,93 (práticas católicas) e 0,76 (práticas espíritas e protestantes).

\section{Procedimento}

Contataram-se inicialmente os responsáveis pelos estabelecimentos de ensino, que deram autorização para a realização da pesquisa. Os participantes responderam os questionários individualmente, em ambiente coletivo de sala de aula. Os instrumentos foram distribuídos por cinco aplicadores treinados para controlar os fatores que pudessem comprometer as respostas dos participantes. Na ocasião, as mesmas instruções foram 
dadas para todos os respondentes, dirimindo-se dúvidas quanto ao formato de resposta, mas não em relação ao conteúdo abordado. Enfatizou-se o caráter voluntário da participação e a garantia de que toda informação seria confidencial. O tempo máximo de resposta foi de 50 minutos.

\section{Análise dos Dados}

Utilizou-se o PASW (versão 18) para calcular estatísticas descritivas (medidas de tendência central, dispersão e frequência), de comparação de médias (teste $t$ de Student) e Alfas de Cronbach. O AMOS foi empregado para realizar as análises fatoriais confirmatórias das medidas de crenças e práticas religiosas. Neste caso, considerou-se a matriz de covariância e foi empregado o método de estimação ML (Maximum Likelihood). O ajuste dos modelos foi analisado com os seguintes indicadores (Byrne, 2001; Marsh, Hau, \& Wen, 2004):

1. $\chi^{2}$ (Qui-quadrado). É um teste de significância do grau em que o modelo se ajusta aos dados, representando valores altos um ajuste ruim.

2. Razão $\chi^{2} / g l$ (graus de liberdade). É considerada uma qualidade de ajuste subjetiva, recomendando-se valores entre 2 e 3 , porém aceitando aqueles até 5 .
3. Goodness-of-fit index (GFI). Medida de variabilidade explicada pelo modelo, considerando-se aceitáveis valores de 0,90 ou mais.

4. Comparative fit index (CFI). Compreende um indicador complementar de ajuste, recomendando-se valor igual ou superior a 0,90 .

5. Root-mean-square error of approximation (RMSEA). É um indicador do ajuste do modelo aos dados; valores próximos de zero sinalizam um ajuste melhor, sendo recomendados aqueles iguais ou inferiores a 0,08 , embora se admita até 0,10 como meritório.

\section{Resultados}

\section{Escala de Crenças Religiosas}

Previamente à realização da análise fatorial confirmatória, avaliou-se a adequação dos itens para representar cada fator teorizado, considerando dois critérios: correlação item-total corrigida $\left(r_{\mathrm{i} . t}\right.$; homogeneidade) e consistência interna do fator. Neste caso, considerou-se o coeficiente Alfa de Cronbach para o conjunto de itens e a possível diminuição deste valor, caso se exclua o item em apreço (indicador de precisão do item). A Tabela 1 apresenta os resultados destas análises.

Tabela 1

Correlação Item-Total e Precisão dos Itens da Escala de Crenças Religiosas

\begin{tabular}{llcc}
\hline & Conteúdo dos Itens & $r_{\text {i.t }}$ & Precisão \\
\hline I - Crenças católicas & 02. Imagens de santos devem ser respeitadas. & 0,68 & 0,87 \\
$(\alpha=0,89)$ & 03. Maria, mãe de Jesus, pode interceder entre Deus e o homem. & 0,70 & 0,87 \\
& 05. É importante fazer a 1a comunhão. & 0,75 & 0,86 \\
07. As crianças devem ser batizadas preferencialmente ainda bebês. & 0,66 & 0,87 \\
09. O Papa é o representante de Deus na terra. & 0,69 & 0,87 \\
& 16. Os santos atendem às promessas dos fiéis. & 0,72 & 0,86 \\
II - Crenças espíritas & 04. A reencarnação é possível. & 0,62 & 0,82 \\
$(\alpha=0,84)$ & 10. É possível a comunicação com pessoas que já faleceram. & 0,64 & 0,81 \\
& 11. As pessoas não morrem, desencarnam. & 0,64 & 0,81 \\
& 13. Existem espíritos mais e menos evolúdos. & 0,62 & 0,81 \\
& 15. As pessoas sofrem as consequências de suas atitudes nas vidas passadas. & 0,59 & 0,82 \\
& 17. Jesus foi um espírito evoluído que passou pela Terra. & 0,61 & 0,82 \\
III - Crenças protestantes & 0,34 & 0,56 \\
$(\alpha=0,60)$ & 01. A vocação para o trabalho é um dom divino. & 0,34 & 0,43 \\
& 06. É necessário vestir-se de maneira composta. & 0,52 \\
08. Os ensinamentos bíblicos devem ser seguidos à risca. & 0,51 & 0,48 \\
& 12. Jesus Cristo é o único intercessor entre Deus e o homem. & 0,39 & 0,53 \\
& 14. Deve-se orar antes das refeições. & 0,50 & 0,50 \\
& 18. Não se deve adorar imagens. & 0,01 & 0,71 \\
\hline
\end{tabular}

Nota. $r_{\mathrm{i} . \mathrm{t}}=$ Correlação item-total corrigida.

Como é possível observar nesta tabela, apenas o item 18 (Não se deve adorar imagens), do Fator III (crenças protestantes), não apresentou homogeneidade satisfatória, isto é, igual ou superior a 0,20 ; destaca-se ainda que as correlações item-total mais baixas corresponderam aos itens deste fator. Porém, mesmo apresentando valores inferiores àqueles encontrados nos demais fatores, estes se situaram acima do previamente mencionado. No que se refere à precisão dos itens, constata-se que, em função de sua homogeneidade baixa, o item 18 compromete a consistência interna do fator crença protestante. Portanto, optou-se por excluí-lo das próximas análises. Posteri- 
Santos, W. S., Gouveia, V. V., Guerra, V. M., Coutinho, M. L. \& Fernandes, D. P. (2012). Índice de Compromisso Religioso (ICR): Elaboração e Evidências Psicométricas.

ormente, buscou-se conhecer a adequação do modelo que agrupa os itens em três fatores de crenças (católicas, espíritas e protestantes).

De acordo com os resultados da análise fatorial confirmatória, a estrutura previamente indicada foi corroborada. Todas as saturações foram diferentes de zero $(\lambda \neq 0 ; z>1,96, p<0,05)$; a menor $(0,42)$ correspondeu ao item 1 ( $A$ vocação para o trabalho é um dom divino), do fator crenças protestantes, sendo que as demais variaram entre 0,51 (É necessário vestir-se de maneira composta) e 0,79 (É importante fazer a $1^{a}$ comunhão), como mostradas na Figura 1. O modelo representado por esta figura apresentou indicadores adequados de ajuste: $\chi^{2}$ $(116)=274,49, p<0,001, \chi^{2} / g l=2,37, \mathrm{GFI}=0,90$, CFI $=0,92$ e RMSEA $=0,066($ IC $90 \%=0,06-0,08)$. Como é possível observar na Tabela 1, os Fatores I (crença católica) e II (crença espírita), com seis itens cada um, apresentaram coeficientes de consistência interna (Alfa de Cronbach) de 0,89 e 0,84 , respectivamente; no caso do Fator III (crença protestante), apesar de ter tido um item eliminado, passando a ser formado por cinco itens, teve Alfa igualmente satisfatório $(\alpha=0,71)$.

\section{Escala de Práticas Religiosas}

De modo análogo ao que ocorreu com a escala anterior, procurou-se realizar análises preliminares para a Escala de Práticas Religiosas, checando posteriormente evidências de sua validade fatorial. Neste sentido, buscou-se inicialmente conhecer as correlações item-total para cada um dos 18 itens que compõem esta medida, como descrito na Tabela 2.

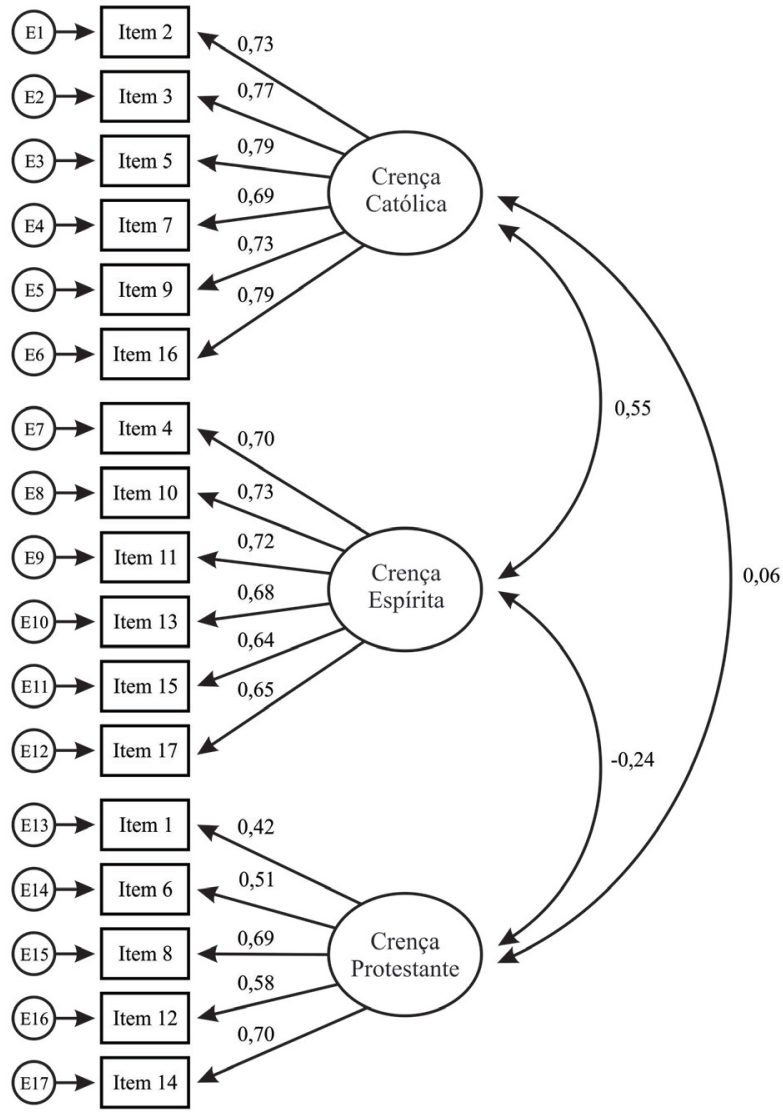

Figura 1. Estrutura multifatorial da Escala de Crenças Religiosas.

Tabela 2

Correlação Item-Total e Precisão dos Itens da Escala de Práticas Religiosas

\begin{tabular}{llcc}
\hline & Conteúdo dos Itens & $r_{\text {i.t }}$ & Precisão \\
\hline I - Prática Católica & 01. Confesso-me com o padre ou durante a missa. & 0,61 & 0,83 \\
$(\alpha=0,85)$ & 02. Assisto à missa. & 0,69 & 0,81 \\
& 06. Sigo os conselhos do padre. & 0,64 & 0,82 \\
& 13. Participo de procissões ou romarias. & 0,68 & 0,82 \\
& 14. Rezo o terço. & 0,66 & 0,82 \\
& 15. Benzo-me ao passar em frente à igreja. & 0,57 & 0,84 \\
II - Prática Espírita & 05. Procuro desenvolver meus dons mediúnicos. & 0,39 & 0,47 \\
$(\alpha=0,56)$ & 07. Tomo água fluidificada (abençoada, purificada). & 0,44 & 0,43 \\
& 08. Procuro a reforma íntima, reduzir os defeitos e vícios. & 0,10 & 0,65 \\
& 09. Converso com pessoas que já morreram. & 0,39 & 0,47 \\
III - Prática Protestante & 16. Leio livros psicografados. & 0,35 & 0,49 \\
$(\alpha=0,65)$ & 03. Dou o dízimo. & 0,48 & 0,60 \\
& 04. Oro antes das principais refeições. & 0,59 & 0,55 \\
& 10. Vou aos cultos da igreja. & 0,62 & 0,53 \\
& 11. Prego o evangelho a outras pessoas. & 0,50 & 0,60 \\
& 12. Participo de eventos profanos (carnaval, boites, etc) & $-0,06$ & 0,78 \\
\hline
\end{tabular}

Nota. $r_{\text {i.t. }}=$ Correlação item-total corrigida. 
De acordo com esta tabela, a maioria dos itens apresentou homogeneidade satisfatória, refletindo nos Alfas de Cronbach de cada fator. Entretanto, os itens 8 [Procuro a reforma íntima (reduzir os defeitos e vícios)], no Fator II (Prática Espírita), e 12 [Participo de eventos profanos (carnaval, boites, etc.)], no Fator III (Prática Protestante), contribuíram para a redução da consistência interna. Portanto, em conformidade com a estratégia adotada na análise da Escala de Crenças Religiosas, decidiu-se excluí-los das próximas análises. Esta decisão tornou o instrumento mais homogêneo, elevando os Alfas de Cronbach para 0,65 e 0,78 nos fatores II e III, respectivamente. Posteriormente, realizou-se uma análise fatorial confirmatória para comprovação da estrutura com os três fatores hipotetizados, considerando-se a versão com 14 itens, resultado das análises prévias. A Figura 2 apresenta esta estrutura.

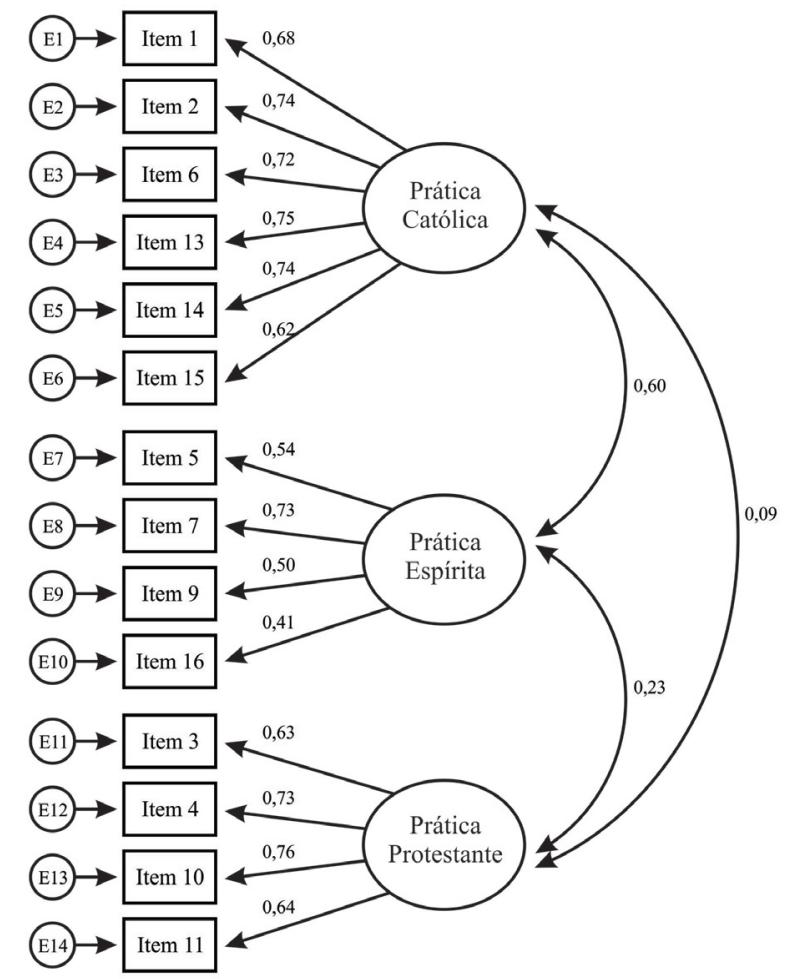

Figura 2. Estrutura multifatorial da Escala de Práticas Religiosas.

A análise fatorial confirmatória comprovou a adequação deste modelo; todas as saturações foram estatisticamente diferentes de zero $(\lambda \neq 0 ; z>1,96, p<0,05)$; a menor delas $(0,41)$ correspondeu ao item 16 (Leio livros psicografados) do Fator II (Prática Espírita), sendo a maior $(0,76$ ) observada para o item 10 (Vou aos cultos $d a$ igreja) do Fator III (Prática Protestante). O modelo apresentou os seguintes indicadores de ajuste: $\chi^{2}(74)=$ $186,41, p<0,001, \chi^{2} / g l=2,52, \mathrm{GFI}=0,92, \mathrm{CFI}=0,92$ e RMSEA $=0,069(\mathrm{IC} 90 \%=0,06-0,08)$.

\section{Discussão Parcial}

Com o fim de atender o objetivo desse estudo, consideraram-se duas medidas independentes de religiosidade: Escala de Crenças Religiosas e Escala de Práticas Religiosas. Inicialmente, verificou-se sua consistência interna e suas estruturas teóricas correspondentes, admitindo-se três fatores (católicos, protestantes e espiritas) tanto para crenças como práticas religiosas. Devido à semelhança das análises e dos resultados, decidiu-se discutir conjuntamente estas duas medidas.

Primeiramente, destaca-se a necessidade de excluir alguns itens destas escalas em função de sua pouca homogeneidade. Porém, verificou-se que esta decisão não as comprometeu; pelo contrário, contribuiu para elevar sua confiabilidade (consistência interna). Este procedimento foi adotado para o Fator III (crença protestante), da Escala de Crenças Religiosas, e os Fatores II (prática espirita) e III (prática protestante), da Escala de Práticas Religiosas. Com relação às análises fatoriais confirmatórias, os resultados apoiaram a coerência do modelo teórico, com três fatores para os dois instrumentos; os indicadores de ajuste observados podem ser considerados apropriados (Byrne, 2001; Marsh et al., 2004), sugerindo a adequação de diferenciar crenças e práticas católicas, espiritas e protestantes.

Finalmente, a especificidade destas medidas deve também ser olhada com algum ceticismo; elas se limitam a mensurar crenças e práticas de três religiões específicas que, embora possam predominar no país, não apreendem o significado último deste construto na população brasileira (IBGE, 2010). Além disso, a heterogeneidade da amostra pode ter influenciado os resultados. Não obstante essas limitações, a utilidade de tais escalas parece evidente, sobretudo quando outros grupos religiosos são menos proeminentes. Ademais, como previamente mencionado, a proposta neste artigo não é considerar indicadores isolados de religiosidade, mas compor um índice geral de compromisso religioso, considerando estas duas medidas, mas não se limitando a elas, como se descreve no Estudo 2.

Estudo 2.

\section{Composição do Índice de Desenvolvimento Religioso}

Este estudo teve como objetivo construir um Índice de Compromisso Religioso (ICR), contemplando múltiplos indicadores, como participação em atividades religiosas, religiosidade autopercebida, além de práticas e crenças religiosas. Neste sentido, seguiu-se procedimento empregado pelas Nações Unidas e Organização Mundial da Saúde para a elaboração de diversos índices, como o $I D H$ ([Índice de Desenvolvimento Humano], Sliwiany, 1997; Ugá et al., 2001). Portanto, fixaram-se valores teóricos mínimo e máximo, de acordo com a escala de resposta e/ ou pontuação total em cada medida, transformando a 
Santos, W. S., Gouveia, V. V., Guerra, V. M., Coutinho, M. L. \& Fernandes, D. P. (2012). Índice de Compromisso Religioso (ICR): Elaboração e Evidências Psicométricas.

pontuação bruta de cada participante de modo a obter para cada indicador um valor variando de 0 (escasso compromisso religioso) a 1 (total compromisso religioso).

\section{Método}

\section{Participantes}

Participaram 194 pessoas da população geral e estudantes universitários, com idade média de 18,4 anos ( $D P=6,24$; amplitude 10 a 43 anos), a maioria do sexo feminino $(67,5 \%)$, declarando-se católica $(48,2 \%)$ e protestante $(40,9 \%)$; alguns indicaram ser espíritas $(3,1 \%)$ e outros se denominaram sem religião $(7,3 \%)$. Tratou-se de amostra de conveniência (não-probabilística), participando as pessoas que, convidadas, concordaram em colaborar.

\section{Instrumentos}

Os participantes responderam um livreto composto pelas Escalas de Crenças e Práticas Religiosas, correspondendo às versões finais descritas no estudo prévio, mantendo-se o mesmo formato de apresentação e escalas de resposta. Incluíram-se também perguntas de natureza demográfica (por exemplo, sexo, idade, estado civil), assim como foram feitas duas perguntas específicas sobre religiosidade: Em que medida você se considera religioso? e Com que frequência você vai às reuniões da sua religião? A primeira deveria ser respondida em uma escala de cinco pontos, variando de $\mathbf{0}$ (Nada religioso) a 4 (Totalmente religioso), e a segunda por meio de uma escala de frequência, variando de $\mathbf{0}$ (Nunca vou) a 7 (Sempre vou).

\section{Procedimento}

O contato com os participantes foi realizado em escolas das redes de ensino público e privado, bem como em reuniões de grupos religiosos católicos, protestantes e espíritas. A aplicação dos instrumentos foi realizada em contextos coletivos, porém as respostas foram dadas individualmente pelos participantes. Esta coleta contou com a colaboração de quatro aplicadores, instruídos para controlar fatores que poderiam comprometer as respostas dos participantes, evitando dar esclarecimentos sobre o conteúdo das medidas; estas eram todas autoaplicáveis. A todos os respondentes foi informado que (a) sua participação seria voluntária, (b) não seria necessária sua identificação e (c) que o anonimato das informações obtidas seria assegurado, explicando que todos os dados seriam tratados estatisticamente no seu conjunto. No caso de escolas com crianças de menor idade, após receber explicações sobre o projeto de pesquisa, os diretores assinaram um termo de responsabilidade, substituindo o Termo de Consentimento Livre e Esclarecido. Em média 40 minutos foram suficientes para completar a participação dos colaboradores da pesquisa.

\section{Resultados}

Prévia à elaboração do Índice de Compromisso Religioso (ICR), realizaram-se três passos principais. Primeiro, em razão do Estudo 1, eliminaram-se os itens: 18 do Fator III (protestante) da Escala de Crenças Religiosas, 8 do Fator II (espirita) e 12 do Fator III (protestante) da Escala de Práticas Religiosas. Segundo, nos casos em que os respondentes indicassem ter outra religião ou pertencer a grupos religiosos minoritários (por exemplo, judeu, mórmon, testemunha de Jeová), atribuíramse constantes para tais medidas. No primeiro caso, fixou-se o valor 1; no segundo, as constantes corresponderam às medianas teóricas das escalas de resposta, isto é, 3 e 4 para as medidas de práticas e crenças religiosas, respectivamente. Finalmente, criaram-se pontuações totais de crenças e práticas religiosas em função da religião do participante. Especificamente, em se tratando dos católicos, foram consideradas unicamente as médias correspondentes aos fatores "práticas católicas" e "crenças católicas"; o mesmo procedimento foi adotado para os espiritas e protestantes.

Assim, criaram-se duas pontuações de compromisso religioso (crenças e práticas), independentemente da religião do respondente. Além destas pontuações, tiveram-se em conta as respostas para as duas outras variáveis de religiosidade: autopercepção acerca do quanto se considera religioso e frequência de participação às reuniões da religião confessada. Como estas variáveis apresentavam métricas diferentes, decidiu-se padronizá-las, criando subíndices de compromisso religioso, admitindo a seguinte equação: Subíndice $=$ (pontuação bruta - valor mínimo) / (valor máximo - valor mínino). No caso, a pontuação bruta correspondeu àquela que os participantes indicaram diretamente e os valores mínimo e máximo disseram respeito aos teóricos, isto é, aos definidos para as escalas de resposta empregadas.

Calculados os quatro subíndices, pareceu indispensável reunir evidências de que estes representavam um mesmo construto latente, cujo marco teórico sugeria nomeá-lo como compromisso religioso. Contudo, previamente comprovou-se a possibilidade de realizar este tipo de análise com o banco de dados tido em conta. Neste caso, os indicadores favorecem pensar na adequação de extrair ao menos um componente: $\mathrm{KMO}=0,74 \mathrm{e}$ Teste de Esfericidade de Bartlett, $\chi^{2}(6)=247,93, p<0,001$. Restaria, entretanto, checar quantos componentes extrair; o critério de Kaiser pareceu suficiente, indicando a existência de um único valor próprio (eigenvalue) maior do que 1 . Os resultados são descritos na Tabela 3. 
Tabela 3

Estrutura Componencial do Índice de Compromisso Religioso

\begin{tabular}{lcc}
\hline Sub-índice & Saturação & $\mathrm{h}^{2}$ \\
\hline Religiosidade auto-percebida & $0,87^{*}$ & 0,76 \\
Frequência às reuniões religiosas & $0,87^{*}$ & 0,76 \\
Crença religiosa & $0,78^{*}$ & 0,61 \\
Prática religiosa & $0,69^{*}$ & 0,48 \\
Valor Próprio & 2,60 & \\
\% Variância Total Explicada & 65,00 & \\
Número de itens / sub-índices & 4 & \\
Alfa de Cronbach & 0,81 & \\
\hline
\end{tabular}

Notas. * Saturação considerada satisfatória $(|0,40|) ; \mathrm{h}^{2}=$ comunalidade.

Como observado, todos os itens (subíndices) apresentaram saturações superiores a $|0,40|$. Considerando que se trata de um único componente, as saturações podem ser consideradas coeficientes de correlação ( $r$ de Pearson), possibilitando calcular, em razão do tamanho da amostra e da magnitude dos coeficientes, se estes são estatisticamente diferentes de zero, o que é corroborado $(p<0,001)$. $\mathrm{O}$ valor próprio deste componente foi de 2,60 , explicando $65 \%$ da variância total e apresentando consistência interna satisfatória $(\alpha=0,81)$.

Em resumo, parecem existir evidências empíricas suficientes que favorecem pensar na adequação de contar com um Índice de Compromisso Religioso. Este reúne diferentes subíndices de religiosidade, representando uma medida independente da religião do participante. Considerando que as saturações de tais subíndices são elevadas, não diferenciando substancialmente entre elas, decidiu-se não ponderar a importância de cada um, admitindo pesos idênticos. Neste sentido, o ICR representou a média dos quatro subíndices, apresentando pontuações variando de 0,13 (religiosidade baixa) a 0,98 (religiosidade alta).

\section{Discussão Geral}

O propósito deste estudo foi construir um índice de compromisso religioso que satisfizesse a três critérios implícitos específicos: validade, precisão e parcimônia. Em função dos resultados, estima-se que tal objetivo tenha sido satisfatoriamente alcançado. Como especificado, em diversas pesquisas a religiosidade ou o compromisso religioso tem sido mensurado por uma diversidade de indicadores (Dalgalarrondo et al., 2004). No entanto, na maioria destas pesquisas tais indicadores são considerados de forma isolada, e naquelas em que se agrupam múltiplas variáveis os resultados são analisados a partir de pontuações médias, sem apresentar qualquer critério de validade e/ou precisão. Neste sentido, os procedimentos aqui adotados sugerem avanços importantes.
Inicialmente, cabe ressaltar que a literatura brasileira apresenta poucos instrumentos destinados à mensuração da religiosidade. O WHOQOL (Fleck et al., 2003), por exemplo, difere consideravelmente do índice proposto neste artigo, por envolver aspectos diferentes, associados à qualidade de vida. Uma das críticas feitas pelos participantes com relação ao uso do WHOQOL sugere que o instrumento "parte do princípio que o indivíduo possui crenças religiosas ou espirituais" (Fleck et al., 2003, p. 454). Neste sentido, o Índice de Compromisso Religioso não assume a religiosidade do indivíduo, mas questiona-o acerca de suas crenças.

Como proposto pela definição de compromisso religioso, a Escala de Religiosidade de Duke (MoreiraAlmeida et al., 2008) também procura mensurar a religiosidade mediante diferentes aspectos. No entanto, este instrumento apresenta apenas cinco itens, divididos em questões sobre a frequência à atividades religiosas, a presença de Deus na vida do indivíduo, a importância das crenças e o esforço pessoal para a vivência da religião. Apesar de relevantes, o reduzido número de itens não permite uma avaliação mais aprofundada do tema, excluindo conteúdos possivelmente relevantes. Além de avaliar diferentes aspectos do compromisso religioso, o ICR apresenta itens relacionados às atividades e crenças dos principais grupos religiosos do país, sugerindo sua relevância.

Portanto, a apresentação do $I C R$ poderá auxiliar novos estudos acerca deste construto. Este aspecto pode ser assegurado, sobretudo, por ser esta uma medida curta, aplicável a indivíduos dos três grupos de crenças religiosas e, inclusive, às pessoas que confessam não ter religião. Como se observou, seus parâmetros psicométricos são considerados bastante aceitáveis. A estrutura fatorial identificada foi coerente com o esperado, ou seja, que os subíndices em conjunto pudessem representar adequadamente a dimensão latente do compromisso religioso; esta interpretação se torna mais inequívoca quando se observa a variância explicada por este componente. Com relação à precisão, pode-se considerar que o ICR apresentou consistência interna (Alfa de Cronbach) satisfatória, uma vez que, mesmo sendo composto por apenas quatro itens, o coeficiente observado foi superior àquele comumente recomendado como ponto de corte $([0,70]$; Pasquali, 2010).

Em síntese, os achados previamente descritos dão conta de evidências de que o ICR é parcimonioso, válido e preciso. No entanto, ao menos duas possíveis limitações deste estudo devem ser reconhecidas, ambas atreladas à amostra. A primeira diz respeito a esta ser de conveniência (não-probabilística), restringindo a generalização dos resultados; e a segunda refere-se à pouca representatividade de alguns grupos religiosos e a especificidade das religiões contempladas nas escalas de crenças e práticas religiosas. Contudo, quanto à pouca representatividade de alguns grupos religiosos, segundo o IBGE (2010), no Brasil observa-se a seguinte distribuição de grupos reli- 
Santos, W. S., Gouveia, V. V., Guerra, V. M., Coutinho, M. L. \& Fernandes, D. P. (2012). Índice de Compromisso Religioso (ICR): Elaboração e Evidências Psicométricas.

giosos: católicos (73\%), protestantes (15\%), espíritas (2\%), pessoas de outras religiões (2\%) e que confessam não ter religião $(8 \%$,$) . Neste sentido, a amostra contemplada não$ discrepa substancialmente da realidade deste país.

Finalmente, em estudos futuros estima-se empregar o $I C R$ para explicar atitudes e comportamentos com os quais se espera o grau de religiosidade ser correlacionado, como valores normativos $(+)$, atitudes favoráveis frente às drogas (-), envolvimento em comportamentos socialmente desviantes (-) e cooperação $(+)$. Estas variáveis poderiam ser tidas em conta como critérios com o fim de conhecer evidências de validade concorrente deste índice.

\section{Referências}

Allport, G. W., \& Ross, J. M. (1967). Personal religious orientation and prejudice. Journal of Personality and Social Psychology, 5, 432-443.

Andrade, J. M., Gouveia, V. V., Jesus, G. R., Santos, W. S., \& Lopes de Andrade, W. C. (2001). Escala de crenças religiosas: Elaboração e validação de construto [Resumo]. In Conselho Regional de Psicologia - 13 $3^{\text {a }}$ Região PB/N (Ed.), $1^{\circ}$ Encontro Paraibano de Avaliação e Medida em Psicologia (p. 14). João Pessoa, PB: Conselho Regional de Psicologia. Byrne, B. M. (2001). Structural equation modeling with AMOS: Basic concepts, applications, and programming. Mahwah, NJ: Lawrence Erlbaum.

Cohen, A. B., \& Hill, P. C. (2007). Religion as culture: Religious individualism and collectivism among American Catholics, Jews, and Protestants. Journal of Personality, 75, 709-742.

Dalgalarrondo, P., Soldera, M. A., Corrêa Filho, H. R., \& Silva, C. A. M. (2004). Religião e uso de drogas por adolescentes. Revista Brasileira de Psiquiatria, 26, 82-90.

Davidson, J. D. (1975). Glock's model of religious commitment: Assessing some different approaches and results. Review of Religious Research, 16, 83-93.

Faria, J. B., \& Seidl, E. M. F. (2005). Religiosidade e enfrentamento em contextos de saúde e doença: Revisão da literatura. Psicologia: Reflexão e Crítica, 18(3), 331-389.

Finney, J. M. (1978). A theory of religious commitment. Sociological Analysis, 39, 19-35.

Fleck, M. P. A., Borges, Z. N., Bolognesi, G., \& Rocha, N. S. (2003). Desenvolvimento do WHOQOL, módulo espiritualidade, religiosidade e crenças pessoais. Revista de Saúde Pública, 37(4), 446-455.

Glock, C. Y. (1962). On the study of religious commitment. Religious Education Research Supplement, 57, 98-110.

Gorsuch, R. L., \& McFarland, S. G. (1972). Single vs. multipleitem scales for measuring religious values. Journal for the Scientific Study of Religion, 11, 53-63.

Instituto Brasileiro de Geografia e Estatística. (2010). Censo demográfico 2010 - Características gerais da população: Resultados da amostra. Retrieved May 01, 2011, from http:/ /www.ibge.gov.br/home/estatistica/populacao/censo2010/

Johnson, B. R., De Li, S., Larson, D. B., \& McCullough, M. (2000). A systematic review of the religiosity and delinquency literature. Journal of Contemporary Criminal Justice, 16, 32-52.

Krohn, M. D., Massey, J. L., Skinner, W. F., \& Lauer, R. M. (1983). Social bonding theory and adolescent cigarette smoking: A longitudinal analysis. Journal of Health and Social Behavior, 24, 337-349.
Longshore, D., Chang, E., Hsieh, S., \& Messina, N. (2004). Self-control and social bonds: A combined control perspective on deviance. Crime Delinquency, 50, 542-564.

Marsh, H. W., Hau, K. T., \& Wen, Z. (2004). In search of golden rules: Comment on hypothesis-testing approaches to setting cut off values for fit indexes and dangers in overgeneralizing $\mathrm{Hu}$ and Bentler's (1999) findings. Structural Equation Modeling, 11, 320-341.

Meira, M., Gouveia, V. V., Socorro, T. C., Oliveira, S. F., \& Silva Filho, S. B. (2001). Escala de práticas religiosas: Construção e validação de construto [Resumo]. In Conselho Regional de Psicologia - $13^{\text {a }}$ Região $\mathrm{PB} / \mathrm{N}$ (Ed.), $1^{\circ}$ Encontro Paraibano de Avaliação e Medida em Psicologia (p. 29). João Pessoa, PB: Conselho Regional de Psicologia.

Mokhlis, S. (2009). Relevancy and measurement of religiosity in consumer behavior research. International Business Research, 2, 75-84.

Moreira-Almeida, A., Lotufo Neto, F., \& Koenig, H. G. (2006). Religiosidade e saúde mental: Uma revisão. Revista Brasileira de Psiquiatria, 28(3), 242-250.

Moreira-Almeida, A., Peres, M. F., Aloe, F., Lotufo Neto, F., \& Koenig, H. G. (2008). Versão em português da Escala de Religiosidade da Duke - DUREL. Revista de Psiquiatria Clínica, 35(1), 31-32.

Panzini, R. G., \& Bandeira, D. R. (2005). Escala de Coping Religioso-Espiritual (Escala CRE): Elaboração e validação de construto. Psicologia em Estudo, 10(3), 507-716.

Panzini, R. G., Maganha, C., Rocha, N. S., Bandeira, D. R., \& Fleck, M. P. (2011). Validação brasileira do Instrumento de Qualidade de Vida/Espiritualidade, religião e crenças pessoais. Revista de Saúde Pública, 45(1), 153-165.

Pasquali, L. (2010). Instrumentação psicológica: Fundamentos e práticas. Porto Alegre, RS: Artmed.

Sanchez, Z. V. D. M., \& Nappo, S. A. (2007). A religiosidade, a espiritualidade e o consumo de drogas. Revista de Psiquiatria Clínica, 34, 73-81.

Schwartz, S. H., \& Huismans, S. (1995). Value priorities and religiosity in four Western religions. Social Psychological Quarterly, 58, 88-107.

Scientific Electronic Library Online. (2011). Religiosidade. Retrieved May 20, 2011, from http://www.scielo.br

Silva, C. G., Santos, A. O., Licciardi, D. C., \& Paiva, V. (2008). Religiosidade, juventude e sexualidade: Entre a autonomia e a rigidez. Psicologia em Estudo, 13(4), 683-692.

Sliwiany, R. M. (1997). Sociometria: Como avaliar a qualidade de vida e projetos sociais. Rio de Janeiro, RJ: Vozes.

Ugá, A. D., Almeida, C. M., Szwarcwald, C. L., Travassos, C., Viacava, F., Ribeiro, J. M., et al. (2001). Considerations on methodology used in the World Health Organization 2000 report. Caderno de Saúde Pública, 17, 705-712.

Wilges, I. (1994). Cultura religiosa: As religiões no mundo. Petrópolis, RJ: Vozes.

Witter, G. P. (2007). Religiosidade: 43 anos de história de um exercício de pesquisa. Revista da Associação Brasileira de Psicologia Escolar e Educacional, 11(1), 153-163. 